Supporting Information

\title{
A Pyrolysis Route for the Conversion of Bacterial Cellulose to Graphene Oxide
}

\author{
Ananda S. Amarasekara ${ }^{* a}$ and Deping Wang ${ }^{a}$ \\ a Department of Chemistry, Prairie View A\&M University, \\ Prairie View, Texas 77446, USA
}

Corresponding authors e-mail: asamarasekara@ pvamu.edu

Number of Pages: 9

Number of Figures: 2

Number of Tables: 0 
Figure S1. Raman spectra of Kombucha pellicle cellulose pyrolyzed products

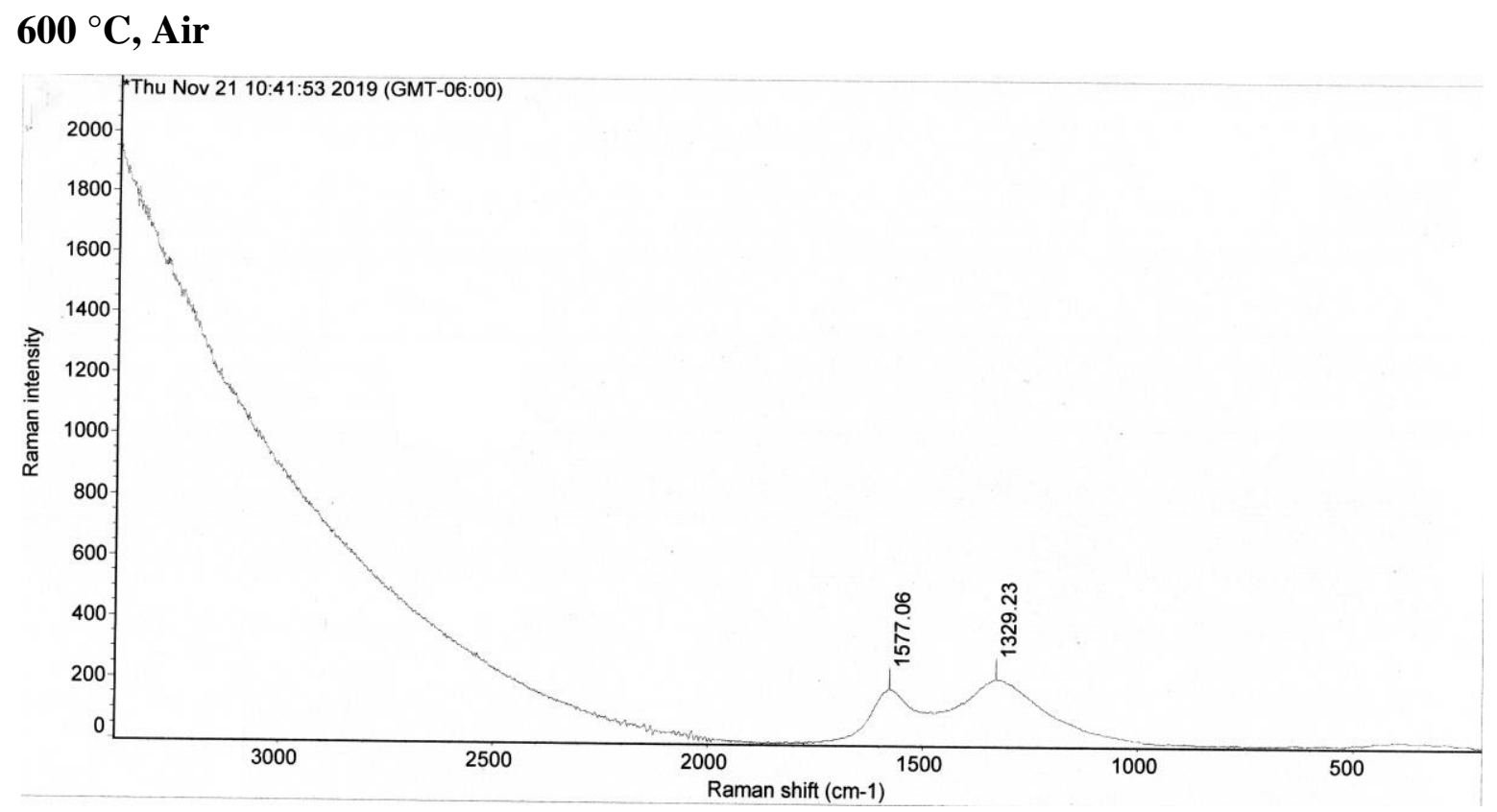

\section{$700{ }^{\circ} \mathrm{C}$, Air}

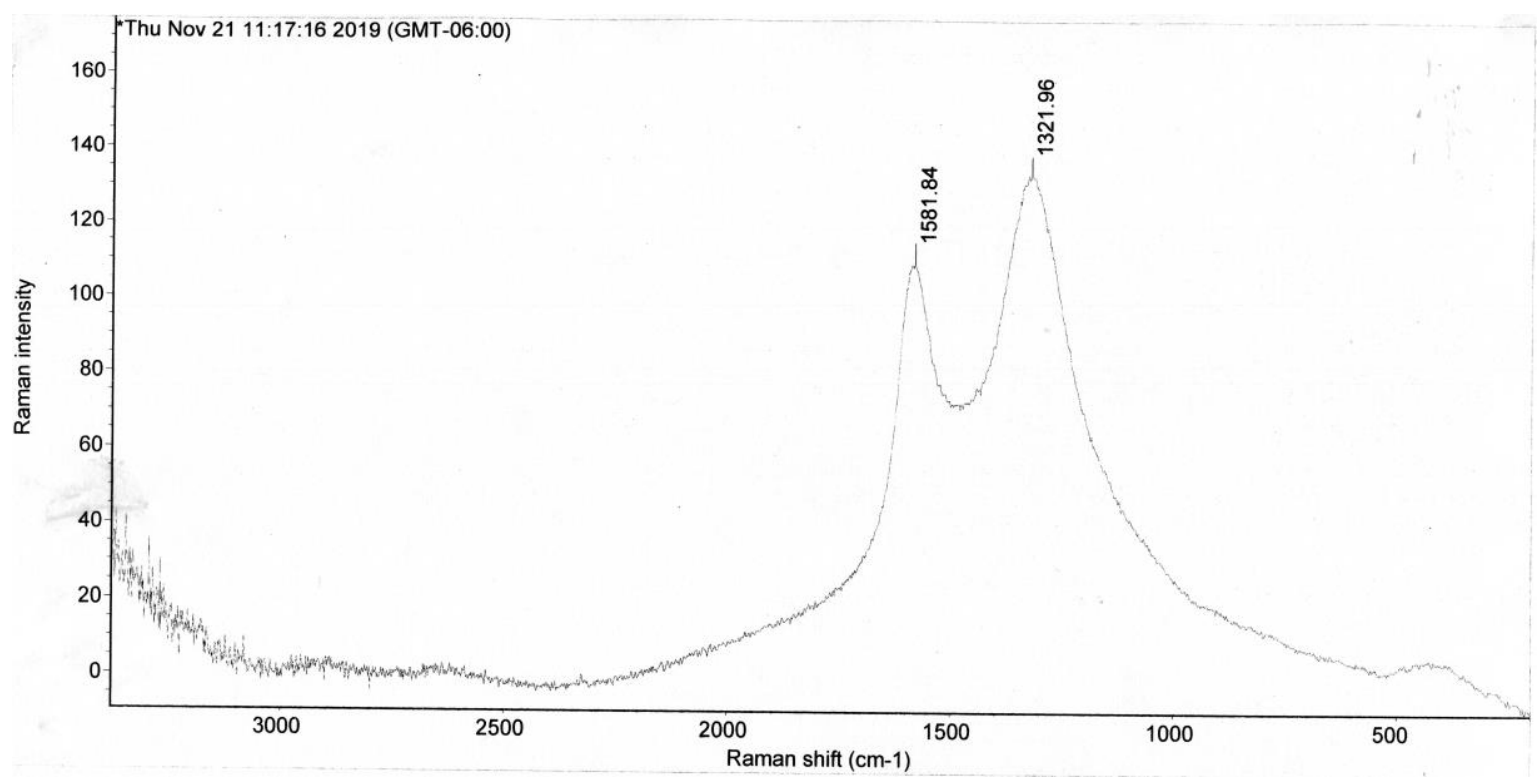




\section{$600{ }^{\circ} \mathrm{C}$, Argon}

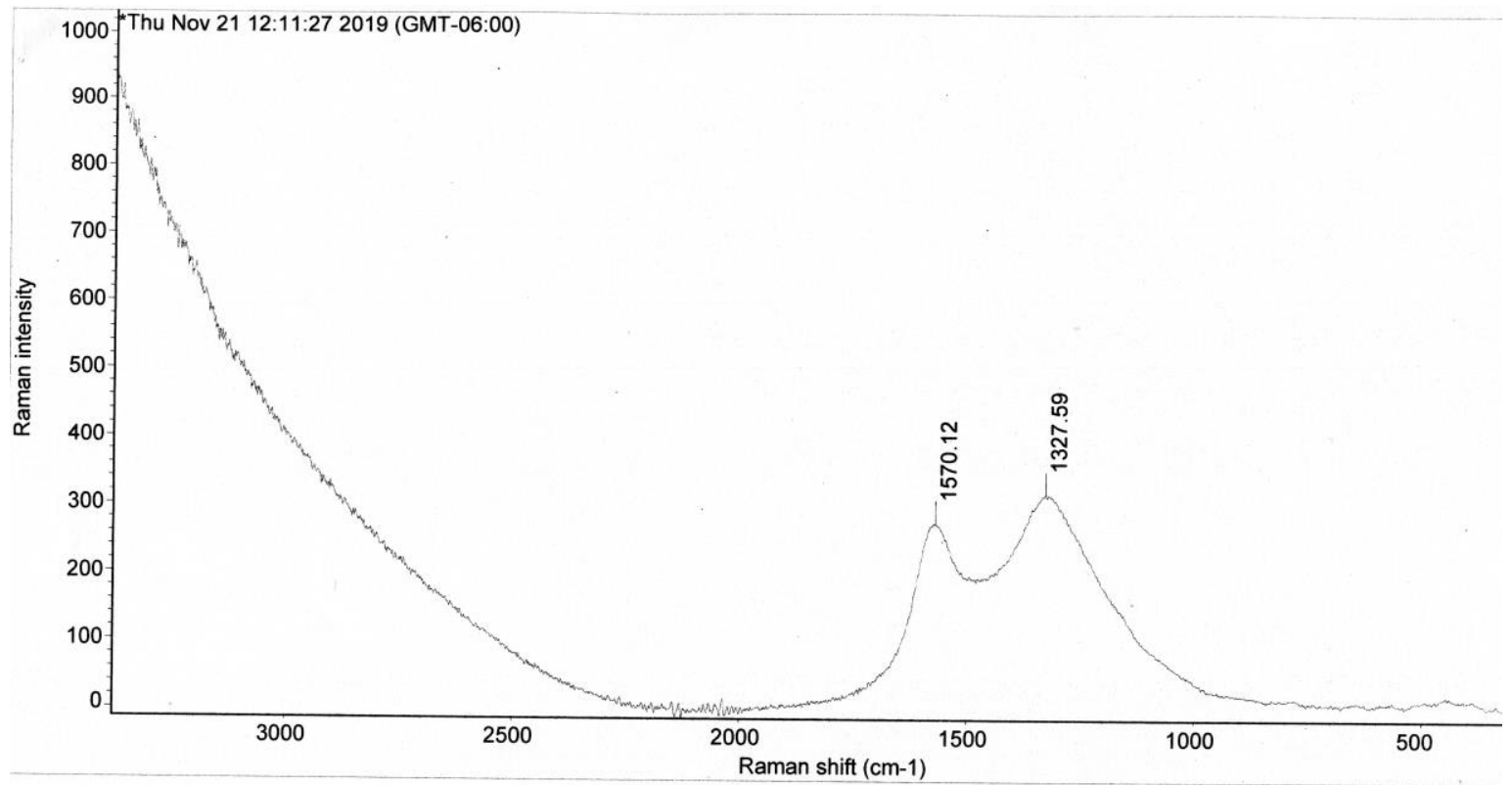

\section{$700{ }^{\circ} \mathrm{C}$, Argon}

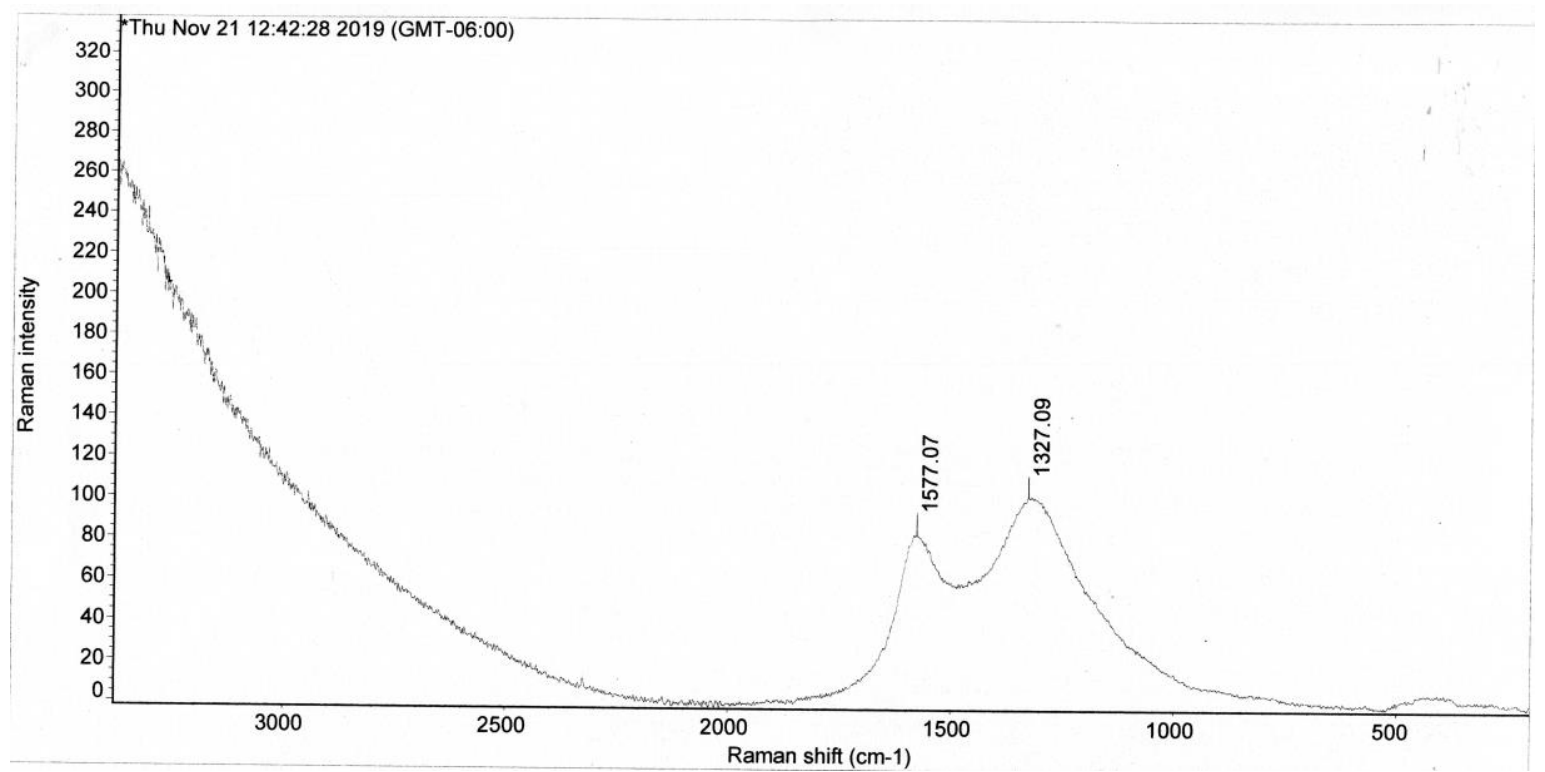


$800{ }^{\circ} \mathrm{C}$, Argon

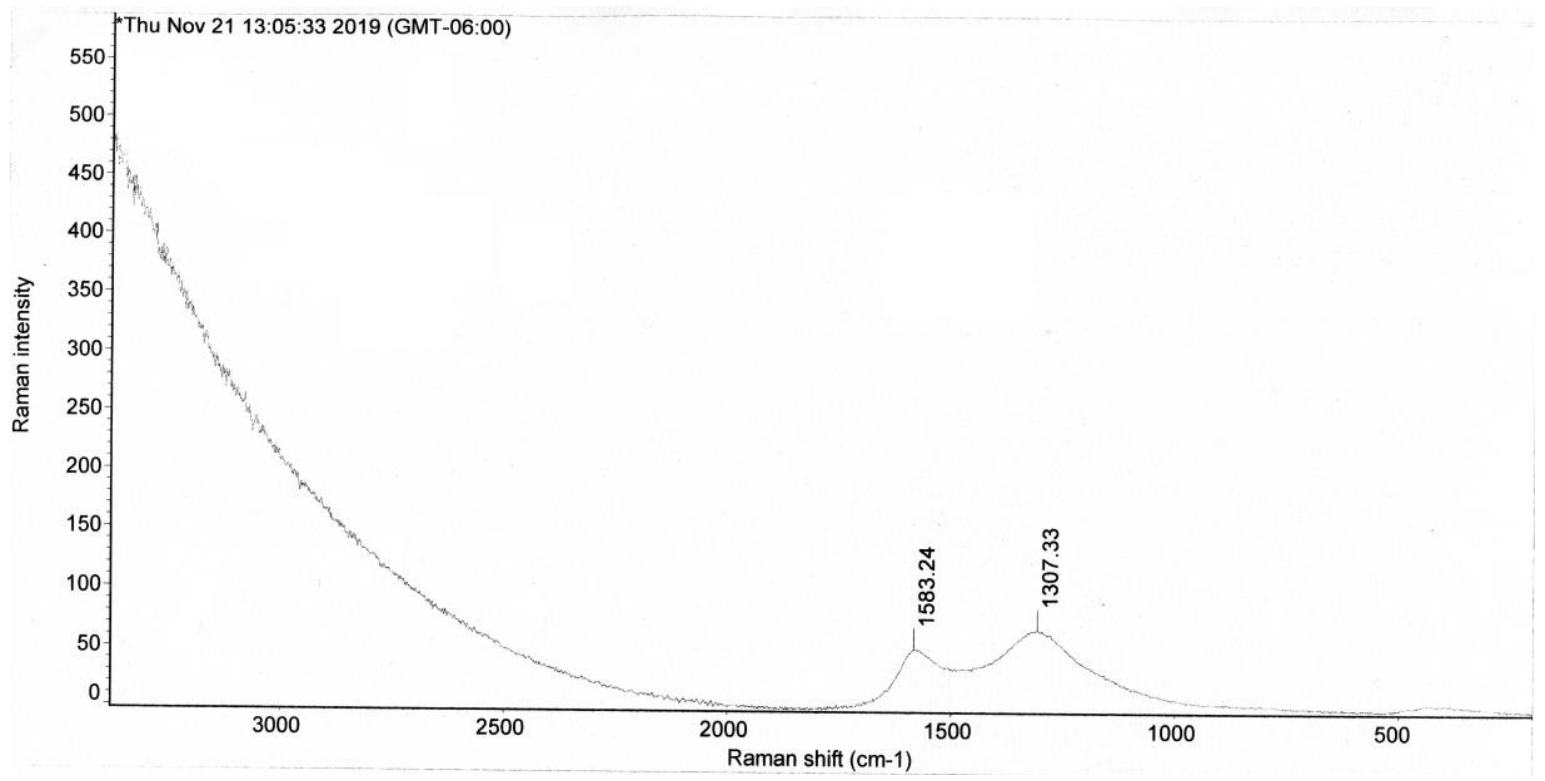


S2. Reflectance FT-IR spectra of room temperature $\left(23{ }^{\circ} \mathrm{C}\right)$ Kombucha pellicle cellulose and samples pyrolyzed to 100, 200, 300, 400, 500, 600, 700 and $800{ }^{\circ} \mathrm{C}$

$23{ }^{\circ} \mathrm{C}$

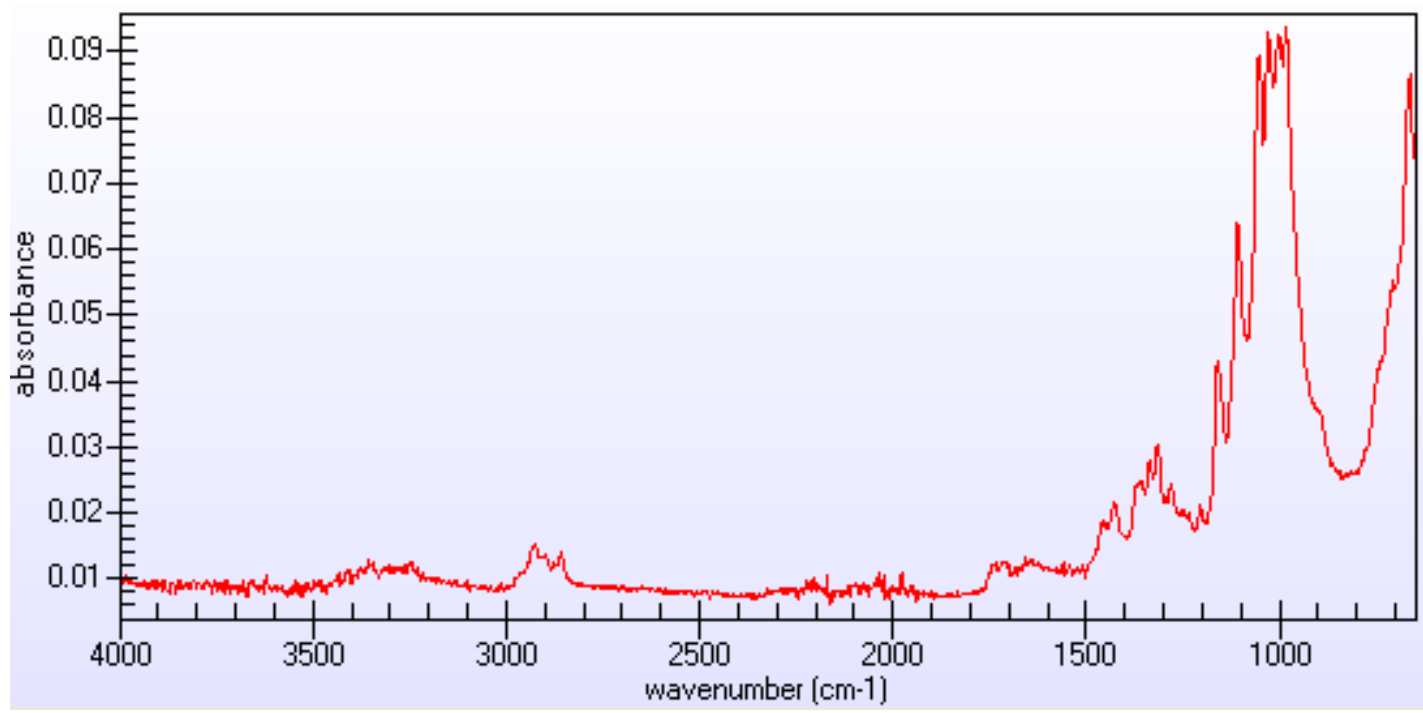

$100{ }^{\circ} \mathrm{C}$

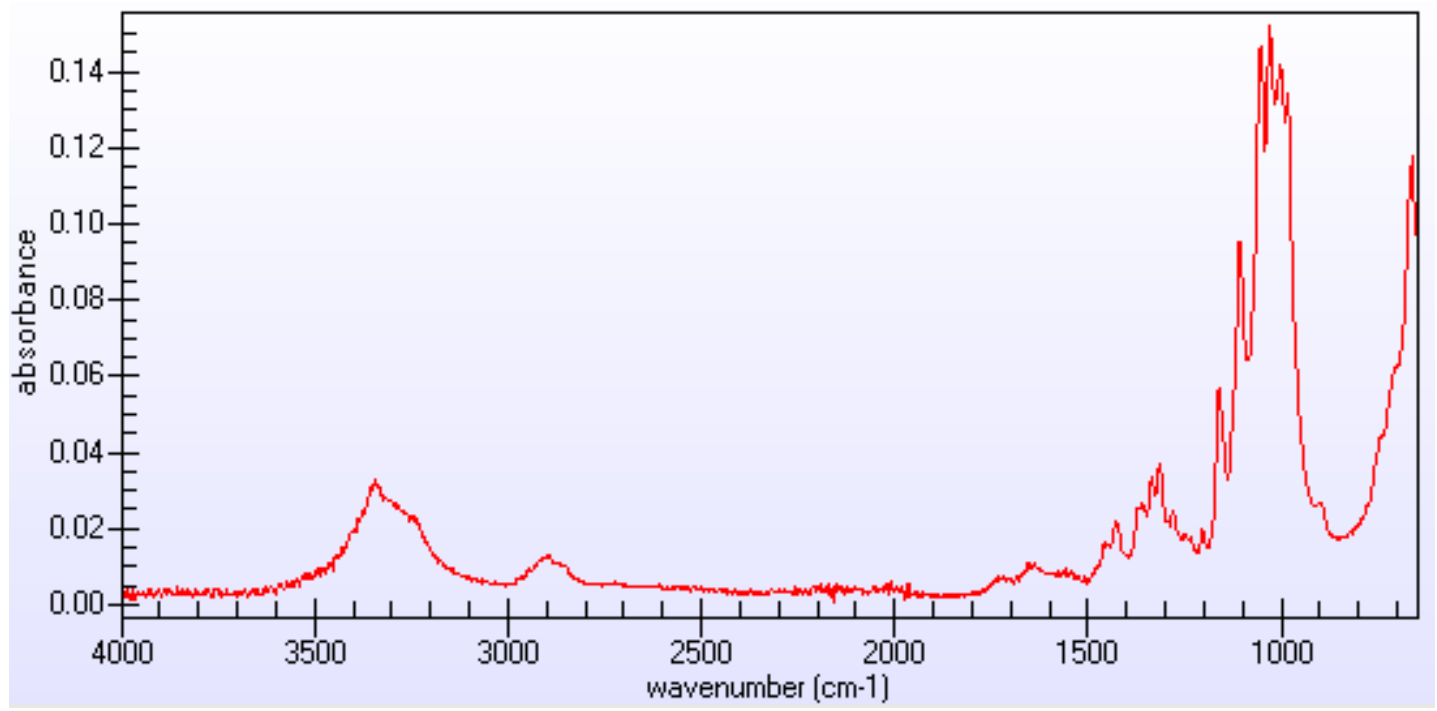


$200{ }^{\circ} \mathrm{C}$

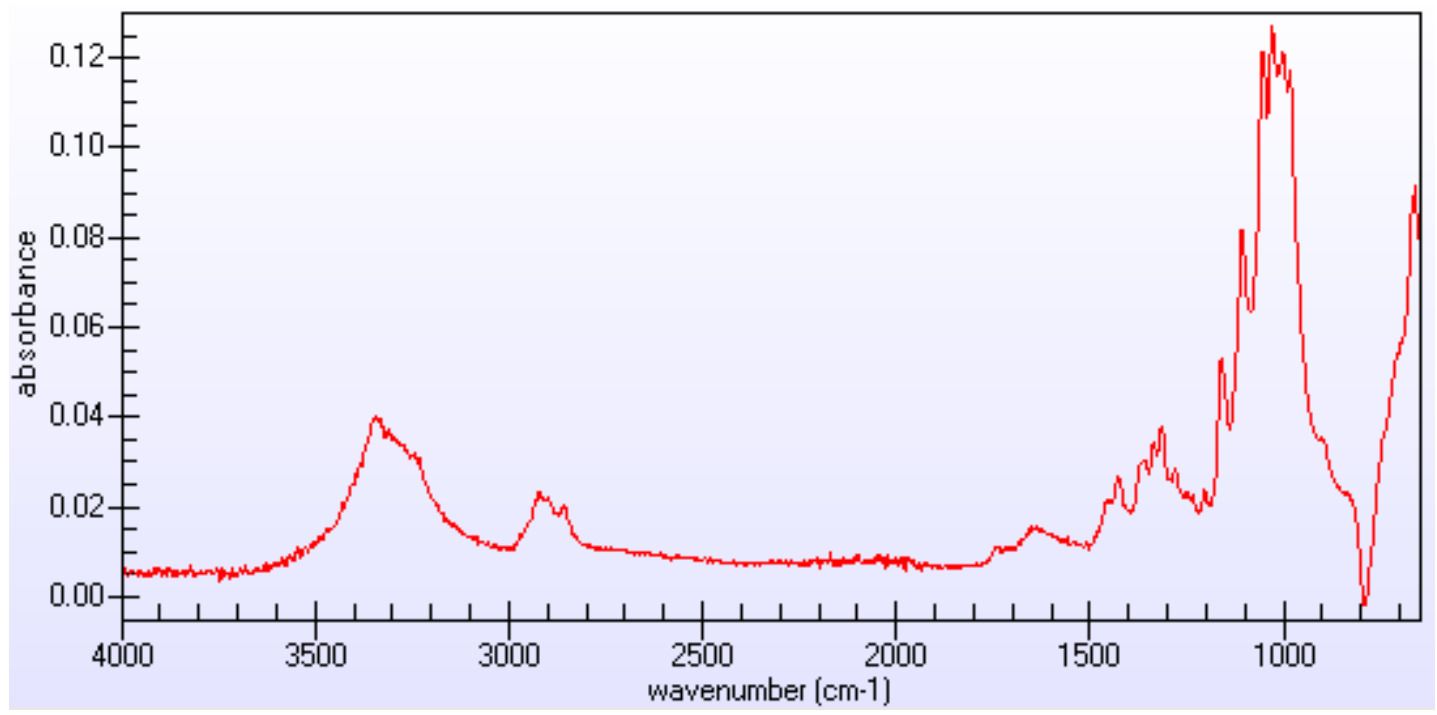

$300{ }^{\circ} \mathrm{C}$

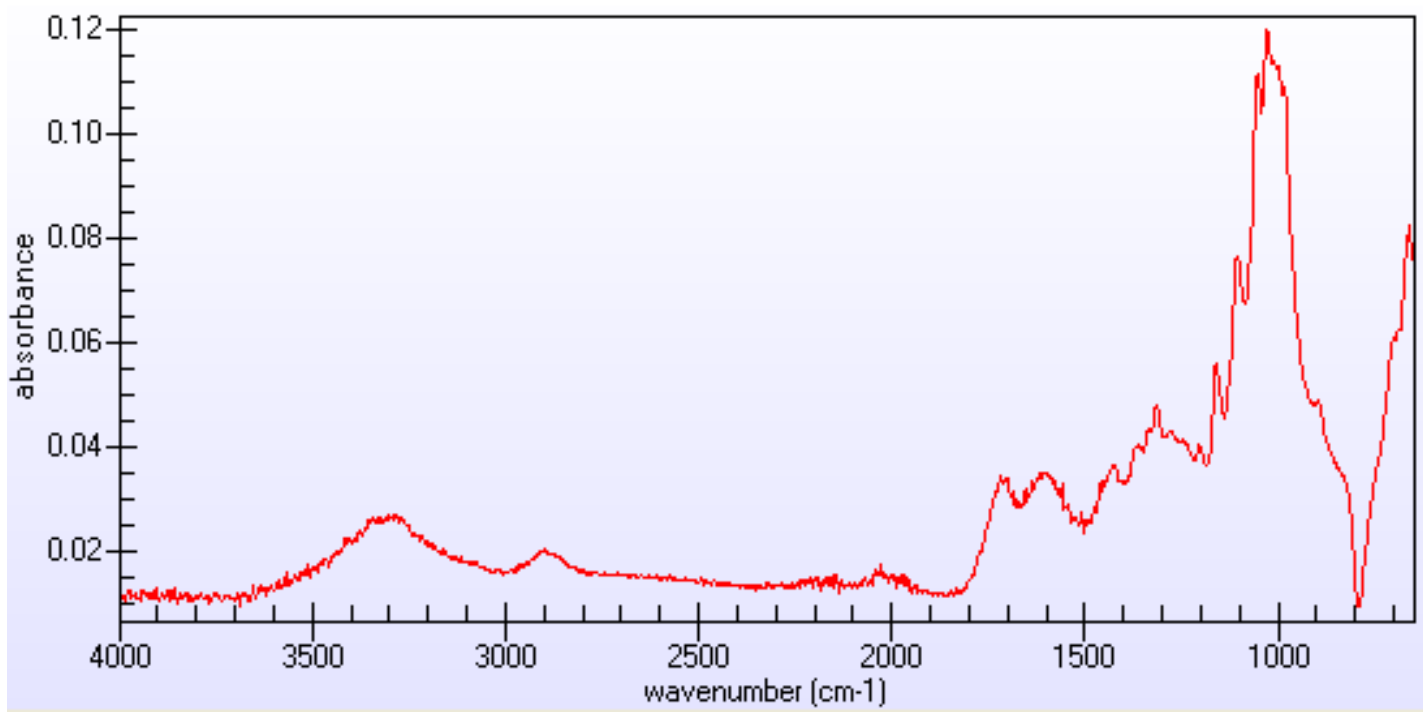


$400{ }^{\circ} \mathrm{C}$

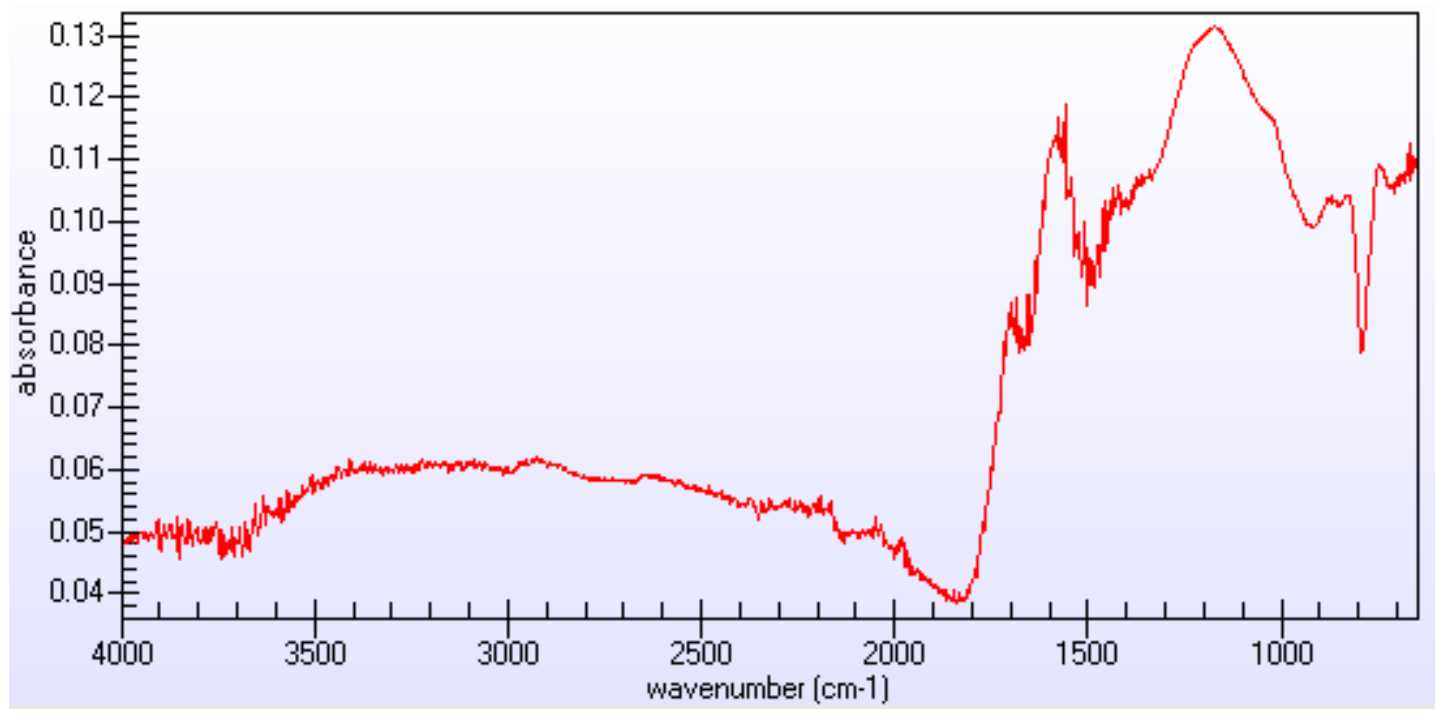

$500{ }^{\circ} \mathrm{C}$

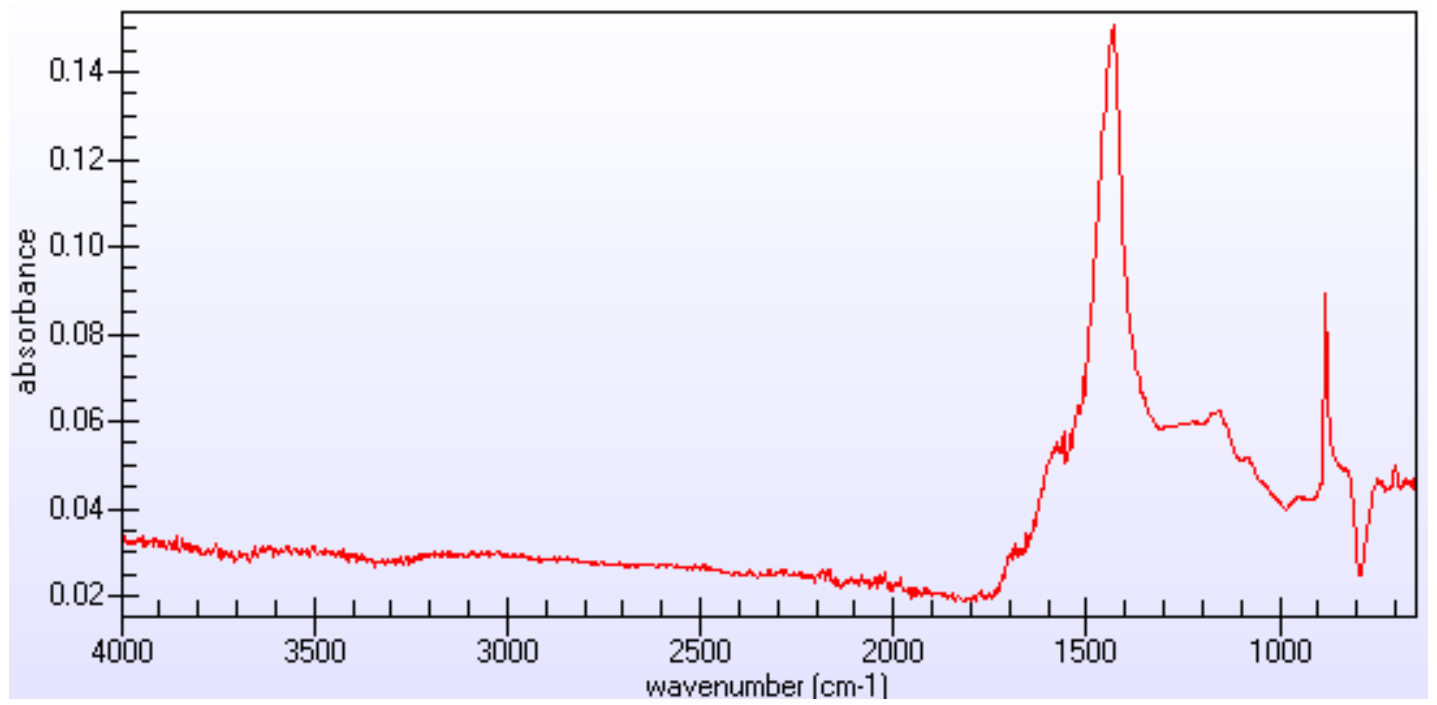


$600{ }^{\circ} \mathrm{C}$

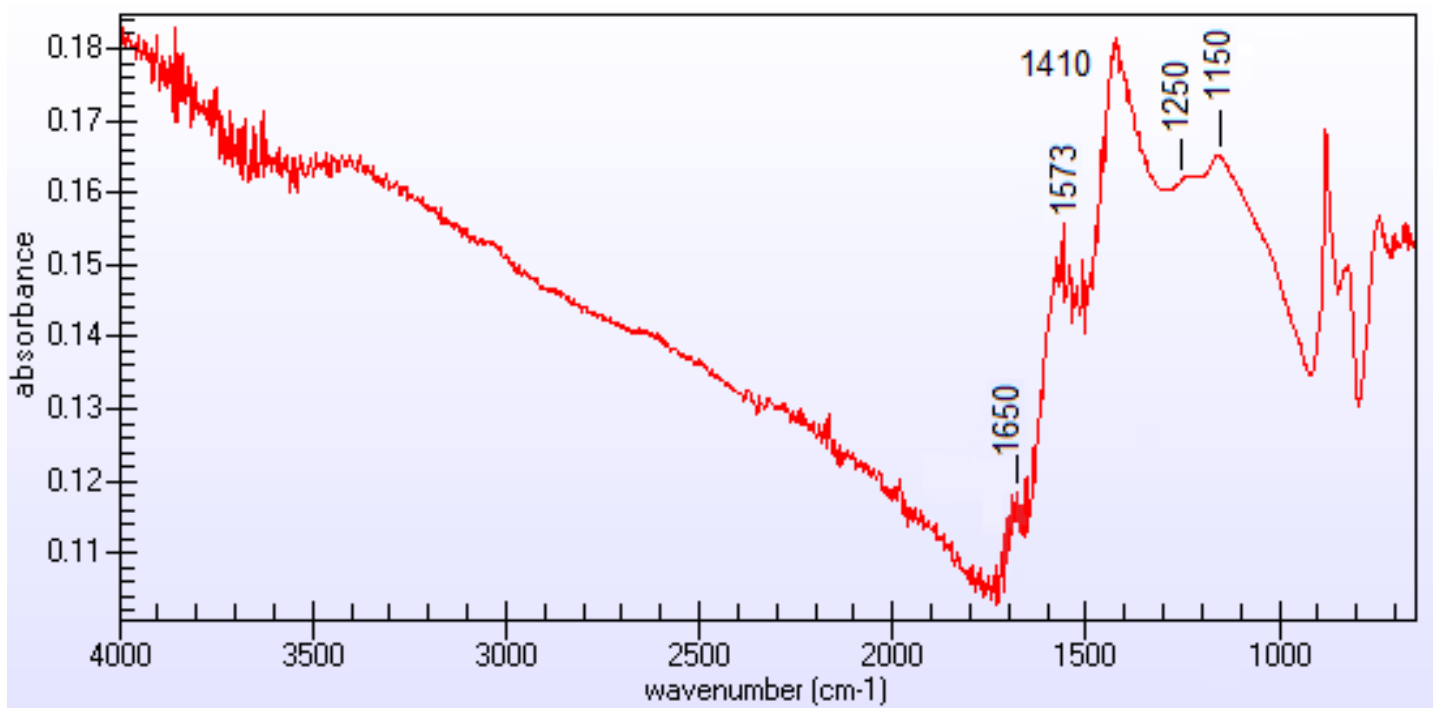

$700{ }^{\circ} \mathrm{C}$

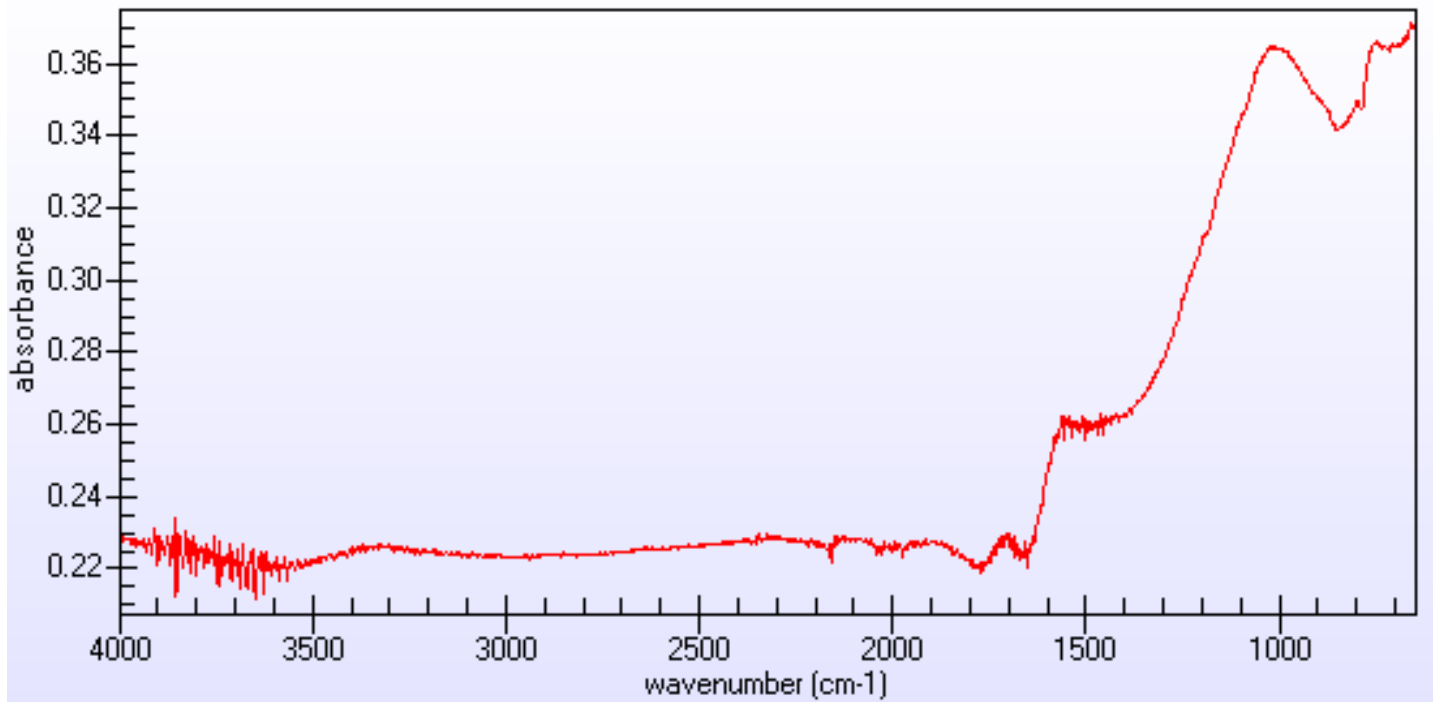


$800{ }^{\circ} \mathrm{C}$

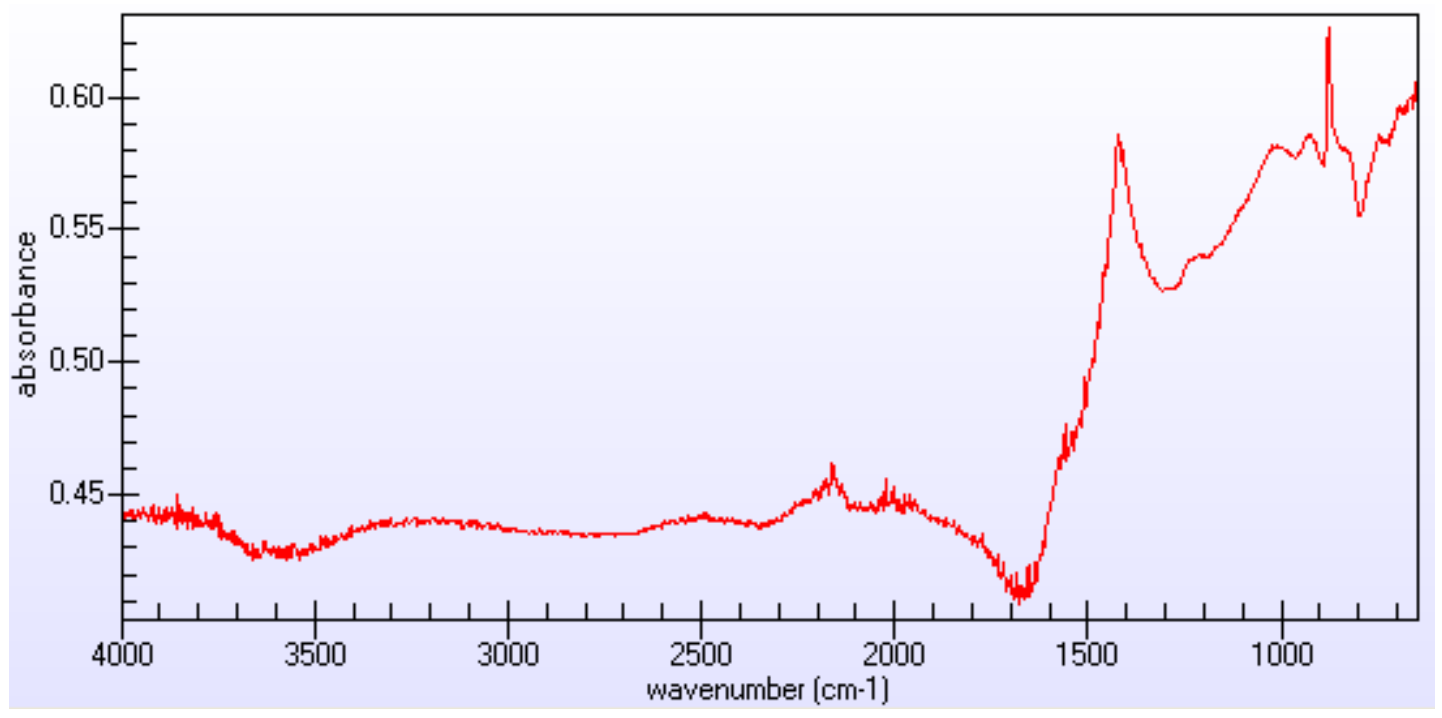

